\title{
Green Power Architecture Considerations for Rural Computing
}

\author{
Sin Giap Yew ${ }^{1}$, Chong Eng $\operatorname{Tan}^{2}$ and Rajan Thangaveloo ${ }^{3}$ \\ Faculty of Computer Science Information Technology, \\ Universiti Malaysia Sarawak \\ Kota Samarahan, Sarawak, Malaysia. \\ sgyew912@yahoo.com.cn ${ }^{1}$, cetan@ieee.org ${ }^{2}$, trajan@fit.unimas.my ${ }^{3}$
}

\begin{abstract}
The introduction of computer technology has brought revolutionary impacts to the living in rural areas. This technology has narrowed the digital divide between the urban and the rural. However, limitation in electricity supply is the major constraint in powering up the Information and Communications Technologies (ICT) equipment in the rural. Consistent electricity supply has become an obstacle in deploying computing systems in the rural environment. Therefore, green and energy efficient power architecture has been proposed in this paper to reduce power wastage and make efficient use of the power for consumption by ICT equipment in order to prolong the operating time of the equipment. Green power architecture can generally be organized into several areas of application such as power sustainability, energy efficiency and reduction in power loss. The effective use of power provision in rural areas has also been taken into consideration. This paper shows that systems that are direct DC powered, wired networked and use solid state Hard Disk Drive (HDD) are more energy efficient and those are the important parameters for rural computing implementation.
\end{abstract}

Keywords-Information and Communications Technologies (ICT); Green Computing Archirecture.

\section{INTRODUCTION}

In rural environment, reliable and affordable electricity supply has always been a serious issue where the source of power can be either not existence or too expensive to generate. Power grid extension is always not an option owing to the high cost of infrastructure investment and the return of investment is too low to justify due to very small population in the rural areas. Rural communities rely heavily on fossil fuel power generator to power up all their electrical and electronic appliances, the problem will be the limited operating hours of the power generator and it is not ideal for the continuous long hour operation as the cost of fossil fuel has been increased drastically from time to time.

Green power architecture which includes power generation, computing devices, and usage pattern can generally be used to ease the limited electricity supply problem in rural areas if adopted appropriately. Renewable energy such as solar power will be one of the options in the search for the alternative power source as it can be obtained easily as long as there is sunlight. This is particular practical in places near the equator where sunlight is always available all year round.

In fact, most of the renewable energy is generated in the Direct Current (DC) form in nature as long as battery system is involved; the power loss during the conversion from Alternating Current (AC) to DC can be avoided if the DC supply can be consumed directly. A lot of electrical and electronic appliances equipped with an AC-DC adapter due to it always assumed that the AC supply is the only form of power source available which is always the case in the urban areas as power coming from power grid. However, this assumption may not be necessary true in the rural areas as power is not supplied via the power grid. The use of AC-DC adapter may not be necessary as the renewable energy generated and the electronics appliances are both in DC nature, only 1-stage DC-DC stepped down conversion is required in order to power up the appliances from the renewable energy source. In conventional system, an inverter is used to convert the DC source into an AC source which is to meet the power requirement of most urban appliances; in such case, a 2 -stages power conversion involved. The power source in DC form will first be converted to AC form as required by the appliances power input unit, then it will be further convert again to the desire DC form by the AC-DC adapter in order to power up the electronics of the appliance. The conversion power loss incurs is still justifiable in the urban area as the power grid always available and it supplies power in $\mathrm{AC}$ form hence only 1-stage conversion is involved; but if the appliance is used in the rural areas and to be powered by renewable energy source, the power loss is significance as 2-stage power conversion is required. Hence, green computing architecture is mandatory in rural areas in order to ease the power shortage problem. 